\title{
Quantifying Wind-driven Rain Intrusion - A Comparative Study on The Water Management Features of Different Types of Rear- Ventilated Facade Systems
}

\author{
Maria Arce-Recatalá1,*, Soledad García-Morales ${ }^{1}$, and Nathan Van den Bossche ${ }^{2}$ \\ ${ }^{1}$ Department of Construction and Technology in Architecture, Technical University of Madrid, 28040 Madrid, Spain. \\ ${ }^{2}$ Department of Architecture and Urban Planning, Ghent University, 9000 Ghent, Belgium.
}

\begin{abstract}
The adequate protection against meteorological conditions of rear-ventilated façades rests on the optimization of the construction design for the joints, cavity depths and wall interfaces. In the late 1990s and early 2000s several authors analysed the water management characteristics of open joints in rainscreen systems, although only few of them attempted to quantify infiltration rates into the air cavity. However, none of these studies provided reliable quantitative data on wind-driven rain intrusion to the water resistive barrier of rear-ventilated façades. The provision of this data will give the means of determining the moisture load to which the façade is to be subjected during a rain event and for which the façade must be able to manage. Consequently, the aim of his paper is to compare quantitatively the water management characteristics of different types of rear-ventilated façade systems by adopting a holistic approach to this kind of enclosure system. In order to conduct this study, three façade systems have been selected based on the type of fixing method and the design of the vertical and horizontal joints. Afterwards, the full-scale mock-ups have been built and tested in controlled laboratory conditions. During these tests, the amount of water infiltrating into the air cavity and the amount of water reaching the water resistive barrier have been measured. Finally, a comparison between the results obtained for every mock-up has been made.
\end{abstract}

\section{Introduction}

Rear-ventilated façades are pressure-equalized rainscreen façade systems. According to ETAG 034 [1] and CWCT [2], rear-ventilated façades are nonloadbearing external cladding assemblies consisting of an outer skin of panels fixed to a framework (specific to the kit or not) which is mechanically fixed to an airtight insulated backing wall. Between the outer skin of panels and the airtight backing wall, a ventilated, drained and pressure-moderated cavity is left. In a pressure moderated rainscreen cladding, the relationship between the area of the open joint which gives access to the cavity void, the volume of the cavity and the air permeability of the air barrier is designed such that wind pressure acting on the face of the rainscreen is balanced by the pressure created at the joint [2]. Therefore, the air gap acts as a pressure cushion to prevent water from reaching the backing wall by means of pressure differences. However, variations in wind speeds, wind direction and hence wind pressure caused by the prevailing conditions, as well as the specific exposure conditions of the wall might impair the pressure equalisation allowing water to bridge the cavity gap at some instances.

The forces acting in support of water ingress in facades are: kinetic energy of raindrops, surface tension, gravity action, pressure differences, local air currents, hydrostatic pressures and capillary forces [3-11]. There is a general belief among researchers that air pressure differential is the major driving force contributing to rainwater penetration [12-14]. Air pressure differences across the walls can be induced by stack effect, mechanical systems and wind [14]. Among these, the higher-pressure differentials might be caused by the wind.

Although the design of rear-ventilated façades typically aims to control all forces that can drive water into the wall assembly (e.g. kinetic energy, surface tension, gravity action, pressure differences, local air currents, hydrostatic pressures and capillary forces), this might not be the case if the forces contributing to rainwater penetration are not adequately considered in the design of the joints and construction details of the facade. For example, there is not a common consensus within the industry about the optimal location of the breather membrane (water resistive barrier) within the rear-ventilated façade build-up and the compartmentation rules for the cavity at the corners are still not clear. Note that the corners are the areas where positive and negative external wind pressures might be experienced at the same time [15].

When a raindrop collides with a rear-ventilated façade, a part of the impinging water is lost by splash, immediate evaporation and absorption by the cladding

* Corresponding author: m.arcer@alumnos.upm.es 
panels if these are porous; a part creates the runoff film along the exterior surface of the cladding; a part remains adhered to the surface of the panels; a part splashes into the air cavity; a part is infiltrated through the open joints; a part remains stagnant within the joints by surface tension and a last part is lost by evaporation inside the air cavity due to the chimney effect. Hence the response of rear-ventilated façades to wind-driven rain present a complex model difficult to predict. Model that might be potentially affected by additional factors such as the secondary structure and fixing system of the cladding panels as these will influence the wetting and runoff patterns.

Therefore, when studying the response of vertical walls to impinging rainwater (study of the effects at and after raindrop impact), three different approaches are taken. On the one side, researchers such as: Blocken et al. [16], de Vogelaere and Pacco [17], Blocken and Carmeliet [18], Chew and Tan [19], Van den Brande et al. [20] amongst others focused their studies on the rainwater runoff from building façades. On the other side, researchers like Couper [21], Rhein [22], Reis et al. [23], Abuku et al. [24], Liu et al. [25] or Erkal et al. [26] studied the contact and surface phenomena such as spreading, splashing and bouncing on vertical building surfaces. And lastly, a third group of researchers (e.g. Birkeland [3, 27], Vos and Tammes [28], Beijer and Johansson [29], Beijer [30], Carll [31], Girma et al. [32], Sahal and Lacasse [33], Lacasse et al. [34-38], TeasdaleSt-Hilaire and Derome [39], Teasdale et al. [40, 41], Bomberg and Shirtliffe [42], Nusselt [43], El-Shimi and Fazio [44], Hall and Kalimeris [45, 46]; Hall and Hoff $[47,48])$ analysed the absorption and the distribution of the moisture within the façade walls. These enclosing not only the rain penetration, but also wetting-drying processes, wetting patterns and surface soiling patterns.

To examine the moisture performance and durability of envelopes and wall assemblies, the prediction of impinging wind-driven rain loads on building façades and the quantification of the water infiltration loads onto the water resistive barrier need to be combined with Heat-Air-Moisture (HAM) models [20]. In HAM models, these parameters are introduced as boundary conditions for the hygrothermal simulation of the wall assembly. However, it should be noted that several secondary effects of wind-driven rain (e.g. splashing and bouncing of raindrops, runoff of rainwater along the surface) have not yet been implemented in current HAM models $[16,20]$.

\subsection{The legal context}

In a context where much of the legislation, regulations, standards and guidance covering the durability and moisture performance of envelopes and wall assemblies is prescriptive and separately treats condensation risk, wind-driven rain risk and flooding [49], only a couple of standards provide the legal framework for the assessment methods for moisture condensation risk: EN 13788 [50] and EN 15026 [51]. EN 13788 [50] gives a simplified calculation method to assess the hygrothermal performance of building components that does not take account of the capillary suction and liquid moisture transfer within materials amongst other limitations. As opposed, EN 15026 [51], which defines the practical application of hygrothermal simulation software to predict one-dimensional transient heat and moisture transfer in multi-layer building envelope components subjected to non-steady climate conditions, specifies that the uptake of wind-driven rain shall be limited by the amount of water that can be absorbed by the material at the surface. However, note that EN 15026 [51] only deals with facades assembled leaving no gaps or open joints between components. Therefore, no consideration is made for any uptake of wind-driven rain onto the back wall as no water is expected to infiltrate to a second leaf in the façade. This construction typology is not representative of rear-ventilated façades, where an outer skin of panels with open joint arrangement is installed in front of a backing wall. In addition, EN 15026 [51] does not cover airflows, 2D issues, as built and in service conditions and the effect of hygroscopic materials on indoor RH [49]. However, these conditions have been incorporated in several non-standardized models (e.g. DELPHIN, WUFI and WUFI 2D) utilizing the method set down in ASHRAE 160 [52]. According to ASHRAE 160 [52], in the absence of specific full-scale test methods and data for the as-built exterior wall system being considered, the default value for water penetration through the exterior surface shall be $1 \%$ of the water reaching that exterior surface. As per the standard, the deposit site for the water shall be the exterior surface of the water-resistive barrier, which in the case of rearventilated façades, typically coincides with the breather membrane location.

In addition to the limitations of current standards, there is lack of data and research on the proportion of wind-driven rain infiltration that reaches the exterior surface of the water-resistive barrier of pressureequalized rainscreen façade systems. In the late 1990s and early 2000s several authors analysed the water management characteristics of open joints in rainscreen systems, although only few of them attempted to quantify infiltration rates. While no field measurements of actual rain infiltration into the backing wall have been documented, some rain infiltration measurements into the cavity of open joint rainscreen systems have been carried out under laboratory conditions [53-68]. These studies did not measure the rain infiltration onto the backing wall, only measured the rain infiltration into the cavity through open joints regardless of the secondary structure and fixing system utilised to hold in place the cladding panels. The provision of this data is evidently important because will give the means of determining the moisture load to which the façade is to be subjected during a rain event and for which the façade must be able to manage. In addition, the rate of rainwater reaching the back wall constitutes the moisture load to the backing wall and can be readily used as input to HAM models, the results of which would be used to assess the vulnerability of wall systems to rainwater ingress. Furthermore, it should be noted that the results obtained with HAM models are particularly sensitive to 
the moisture loads assumed for the model [52]. In this sense, Abuku et al. [69] concluded that simulations typically tend to overestimate the measured average moisture content in façades. Additionally, Arce-Recatala et al. [70] found that an approximately $0.54 \%$ of the wind-driven rain infiltrates onto the surface of the waterresistive barrier of rear-ventilated facades, when this is located on the outer side of the thermal insulation layer.

Therefore, very few reliable quantitative data has been provided on wind-driven rain intrusion for rearventilated façades up to now. Furthermore, the data provided has demonstrated to be significantly smaller to the moisture load percentages suggested in the standards for hygrothermal simulations. These variations in the percentages utilised as outputs for the hygrothermal simulations might not only affect the precision of the results but also the accuracy. Consequently, the aim of his paper is to compare quantitatively the water management characteristics of different types of rearventilated façade systems by adopting a holistic approach to this kind of enclosure system in an effort to propose reliable quantitative data on wind-driven rain intrusion.

\section{Experimental method}

In order to conduct this study, three rear-ventilated façade systems have been selected based on the type of fixing system, the secondary structure utilised to hold in place the cladding panels and the vertical and horizontal joints arrangement. Afterwards, three full-scale mockups have been built using best construction practices and tested in controlled laboratory conditions. During these tests, the amount of water infiltrating into the air cavity and the amount of water reaching the water resistive barrier have been collected in two different gutters located beneath the test specimens. The water collected in each gutter has been poured into buckets through plastic tubes. These buckets stood on weighting scales which recorded the weight over time and thus the rate of water ingress has been measured.

A rainscreen cladding made of fibre cement panels with similar panel arrangement has been used in the three mock-ups to avoid having completely different response scenarios to wind-driven rain and driving rain wind pressures of the cladding material.

Evaluations have been made using sprayed water to simulate wind-driven rain and pressure differences to mimic driving rain wind pressures. These parameters have been set in the tests according to those prescribed in European watertightness test standards. However, as the test protocols provided in current standards (e.g.: EN 12865 [78], EN 12155 [247], EN 1027 [358] and CWCT Standard [2]) are designed to provide qualitative information on the degree of watertightness, a new test procedure has been developed based on the tests procedures described in the standards to allow the quantitative analysis of the results. According to the new procedure, the test specimens have been subjected to a continuous and constant film of water during a period of $15 \mathrm{~min}$ at no pressure difference and at each pressure difference step applied (150, 300, 450, 600 and 750Pa). A row of evenly spaced water spray nozzles has been utilised to deposit water at a rate of $2 \mathrm{~L} / \mathrm{min}$ per $\mathrm{m} 2$ over the outermost surface of the three test specimens.

The stack effect has not been reproduced during the tests. The stack effect is characteristic of rear-ventilated façade systems and depends on the temperature differences across the cavity. However, it was not reproduced as usually when there is a heavy downpour the temperature differences are slight given the reduced solar radiation on the exterior surface of the cladding during such type of rain events.

The wall specimens were intended to be representative of a section of the selected rear-ventilated façade system, except that instead of erecting a brick masonry wall or SFS as interior layer, a transparent acrylate plate (PMMA) of $1 \mathrm{~cm}$ thickness was installed. The PMMA sheet also replaced the thermal insulation layer and acted as the air barrier and water resistive barrier in the façade test specimens evaluated.

\subsection{Mock-up 01}

The first mock-up (mock-up 01) consisted on a fibre cement cladding directly fixed to top hat sections by means of rivets. Below is presented a summary of the main features of mock-up 01:

- Secondary structure: vertical top hat sections

- Fixing system: riveted

- Cavity depth: $95 \mathrm{~mm}$ (including secondary structure)

- Cladding orientation: portrait fibre cement panels

- Joints: 5 open vertical joints and 1 open horizontal joint $10 \mathrm{~mm}$-wide

\subsection{Mock-up 02}

The second mock-up (mock-up 02) comprised a fibre cement cladding hook on horizontal " $C$ " sections by means of hangers fixed to the rear of the panels with undercut anchors. The horizontal " $C$ " sections have been screwed to vertical " $\mathrm{T}$ " profiles. Below is presented a summary of the main features of mock-up 02 :

- Secondary structure: vertical "T" sections and horizontal "C" rails

- Fixing system: hook-on

- Cavity depth: $116 \mathrm{~mm}$ (including secondary structure and fixing system)

- Cladding orientation: landscape fibre cement panels

- Joints: 5 open horizontal joints and 2 open vertical joints $10 \mathrm{~mm}$-wide

\subsection{Mock-up 03}

The third mock-up (mock-up 03) consisted on a fibre cement cladding directly fixed to vertical " $T$ " sections by means of rivets. Below is presented a summary of the main features of mock-up 03:

- Secondary structure: vertical "T" sections

- Fixing system: riveted 
- Cavity depth: 88mm (including secondary structure)

- Cladding orientation: landscape fibre cement panels

- Joints: 2 open vertical joints and 5 open horizontal joints 10mm-wide

\section{Results}

\subsection{Water infiltrated into the cavity}

The graph plotted in Figure 1 shows the water infiltration rates into the cavity for all three types of rearventilated façade systems studied as function of applied pressure differences in front of the cladding and for a spray rate of approximately $2 \mathrm{~L} / \mathrm{min}$ per $\mathrm{m}^{2}$.

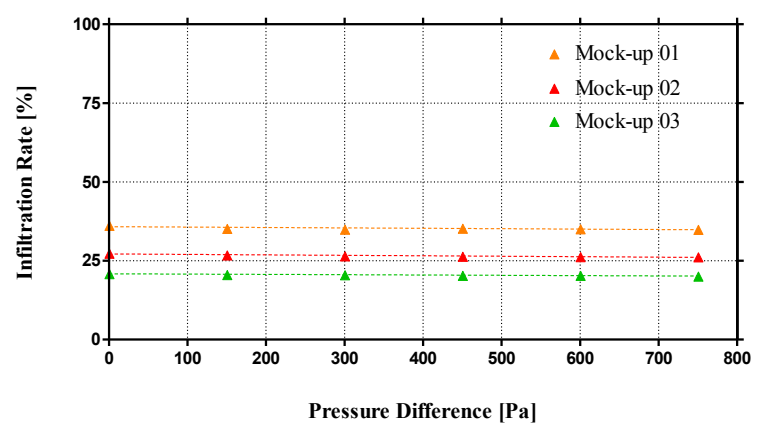

Fig. 1. Comparison amongst water infiltration rate percentages into the cavity of mock-up 01 , mock-up 02 and mock-up 03 as function of applied pressure differences in front of the cladding.

It appears that constant water collection rates into the cavity have been recorded for increases in the applied pressure differences in the three types of rear-ventilated façade systems. These results evidence that there is no driving pressure acting on the water infiltration through the tests specimens as it would have been expected for a pressure-equalized façade system.

From the graph shown in Figure 1 it is also evident that the highest water infiltration percentages into the cavity have been obtained for the rear-ventilated façade system made of fibre cement cladding panels riveted to vertical top hat sections (mock-up 01). Note that this cladding comprised 5 open vertical joints and 1 open horizontal joint in an exposed surface of approximately $3.9 \mathrm{~m} 2$. As opposed, the lowest infiltration rate percentages have been obtained for the rear-ventilated façade system consisting on fibre cement cladding panels riveted to vertical " $T$ " sections (mock-up 03). In this case, the cladding arrangement contained 2 open vertical joints and 5 open horizontal joints in an exposed surface of approximately $2.6 \mathrm{~m} 2$. Note that mock-up 02 , which reported intermediate infiltration rate percentages, simulated a hook-on rear-ventilated façade system with a cladding arrangement containing 2 open vertical joints and 5 open horizontal joints in an exposed surface of approximately $3.5 \mathrm{~m}^{2}$.

Nevertheless, when the infiltration rate percentages are weighted as function of the exposed surface of the test specimens for each rear-ventilated façade system, the results vary a little bit (refer to Figure 2).

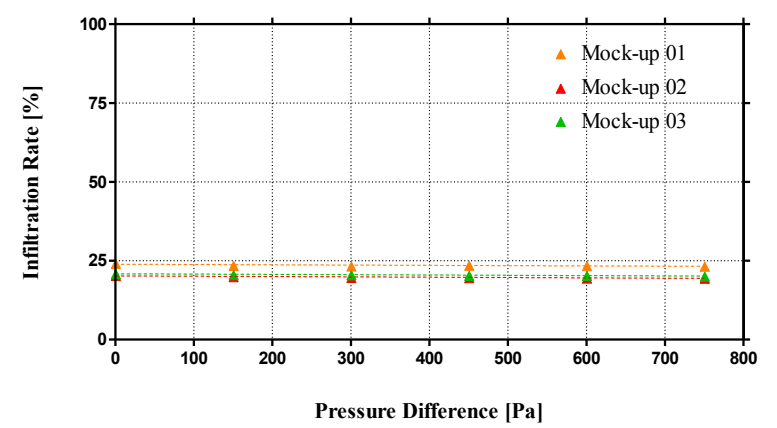

Fig. 2. Comparison amongst the area weighted water infiltration rate percentages into the cavity of mock-up 01 , mock-up 02 and mock-up 03 as function of applied pressure differences in front of the cladding.

In the area weighted results, the higher water infiltration rates into the cavity are still obtained for the rear-ventilated façade system made of fibre cement cladding panels riveted to vertical top hat sections (mock-up 01). The water infiltration rate percentages into the cavity for the test specimens with fibre cement cladding panels riveted to vertical " $T$ " sections (mock-up 03) and fibre cement cladding panels hook on horizontal "C" sections (mock-up 02) are more similar. However, the water infiltration percentages in the rear-ventilated façade system with fibre cement cladding panels riveted to vertical " $T$ " sections (mock-up 03) are slightly above the rear-ventilated façade system with fibre cement cladding panels hook on horizontal " $\mathrm{C}$ " sections (mockup 02).

These results suggest that more water infiltrates into the cavity through the rear-ventilated façade systems, whose cladding kits have more exposed openings (e.g.: joints and rivet holes). Furthermore, the capillary pathways created between the cladding panels and the vertical profiles installed behind the panels at the vertical joint locations (baffled joints) promote higher water ingress rates into the cavity than normal open joints.

\subsection{Water reaching the water resistive barrier}

The graph plotted in Figure 3 records the water infiltration rate percentages onto the water resistive barrier of the three test specimens built to simulate the varying types of rear-ventilated façade systems. These water infiltration percentages are given as function of the applied pressure differences in front of the cladding and for a spray rate of approximately $2 \mathrm{~L} / \mathrm{min}$ per $\mathrm{m}^{2}$. 


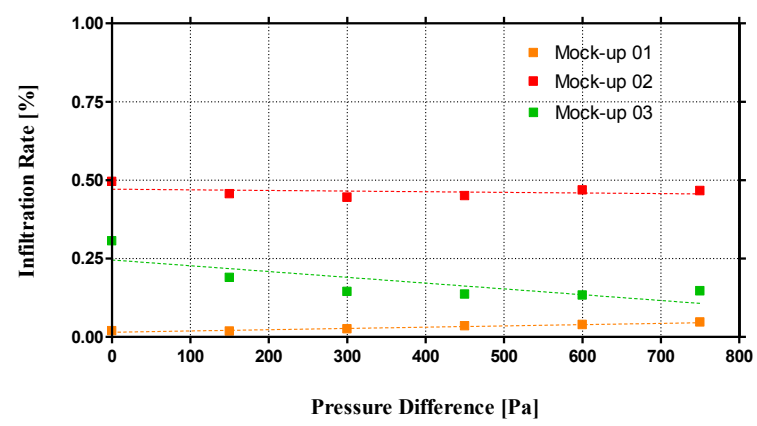

Fig. 3. Comparison amongst water infiltration rate percentages reaching the water resistive barrier of mock-up 01, mock-up 02 and mock-up 03 as function of applied pressure differences in front of the cladding.

Apparently, constant water collection rates to the water resistive barrier have been recorded for increases in the applied pressure differences in the rear-ventilated façade system made of fibre cement cladding panels riveted to vertical top hat sections (mock-up 01) and the hook-on rear-ventilated façade system (mock-up 02). As opposed, it appears that increasing pressure differences in front of the cladding have led to lower infiltration rates onto the water resistive barrier of the test specimen with fibre cement cladding panels riveted to vertical " $T$ " sections (mock-up 03). These results suggest that higher pressure differences provide water droplets with more kinetic energy and thereby, water droplets have a higher splash and bounce effect and are able to reach longer distances through open joints.

When measuring the amount of water reaching the water resistive barrier of the three test specimens, slightly different rates of water entry have been obtained for the evaluated rear-ventilated façade types. As expected, the highest amount of water reaching the water resistive barrier has been reported in the test specimen simulating a hook-on rear-ventilated façade system (mock-up 02). In this façade system, the vertical and horizontal joints present in the cladding are completely open. Conversely, the lower infiltration rate percentages onto the water resistive barrier have been obtained in the test specimen with fibre cement panels riveted to vertical top hat sections (mock-up 01). This was also a foreseeable result as the vertical joints were baffled. The vertical top hat profiles installed behind the panels at the vertical joint locations acted as pipes and prevented water reaching the surface of the polycarbonate sheet (water resistive barrier in the test specimen). Therefore, the water infiltration rate percentages reported in the graph given in Figure 3 for mock-up 01 are the result of the water infiltrated through one open horizontal joint. Regarding the water infiltration rate percentages obtained for the test specimen with fibre cement cladding panels riveted to vertical " $T$ " sections (mock-up 03 ), slightly higher water ingress rates were obtained compared to the test specimen with fibre cement panels riveted to vertical top hat sections (mock-up 01). However, these percentages are the result of the water ingress through five open horizontal joints as the vertical joint is baffled by means of a "T" vertical section. The
" $T$ " vertical section installed behind the panels at the vertical joint locations impeded water directly reaching the surface of the polycarbonate sheet.

These results suggest that open joints lead to higher infiltration rates onto the surface of the polycarbonate sheet when compared to baffled joints. Furthermore, in similar rear-ventilated façade systems (mock-up 01 and mock-up 03), it has been observed that the number of open joints also affects the water infiltration rate percentages onto the surface of the polycarbonate sheet. Note that the water load applied to the outermost surface of the three test specimens was carried out via a single spray bar with nozzles evenly spaced. Therefore, higher infiltration rate percentages might be expected when the water load is projected over the test specimen surface by means of a matrix of nozzles evenly spaced.

In addition, the results have also evidenced that the more complex and the more elements the secondary structure and the fixing system have, the higher the amount of water that might reach the polycarbonate surface as more surfaces to splatter away are provided.

\section{Discussion}

Three types of rear-ventilated façade systems have been subjected to a sequence of watertightness test procedures obtaining that approximately $25 \%$ of the sprayed water infiltrated into the cavity of the test specimens and less than $0.5 \%$ of the sprayed water was able to reach the water resistive barrier. This water ingress percentages measured in the three evaluated rear-ventilated façade systems are not in line with the infiltration percentages provided in the few existing studies for rainscreen systems. For instance, the study carried out by the FVHF [71] reported that $16.6 \%$ of the sprayed water infiltrated inside the air cavity and $0.4 \%$ reached the exterior surface of the thermal insulation layer in a rainscreen system with open vertical and horizontal $8 \mathrm{~mm}$ wide joints and an air gap of $100 \mathrm{~mm}$. The difference with the results shown in this paper is difficult to attribute, given that the testing procedure, spraying system, secondary structure and fixing system of the cladding kits are not indicated in the study carried out by the FVHF.

Mas et al. [57] tested a rainscreen system made of stone plaques fixed by anchors to a supporting frame obtaining a $55 \%$ of water infiltration inside the air cavity through vertical and horizontal joints $8 \mathrm{~mm}$ wide. This percentage almost doubles the highest water infiltration rates we have obtained in the present study. This difference can perhaps be explained by considering factors that might have contributed to variations in water deposition to the surface of the test specimen (e.g.: spraying system, distance to the outermost surface of the specimen, spray rate and so on).

On another study, Fernández-Madrid [58] found that $5.81 \%$ of the total projected water infiltrated inside the air cavity, when a rainscreen wall was subjected to positive pressure pulsations at a water spray load of 2.7 $\mathrm{L} / \mathrm{min} \cdot \mathrm{m}^{2}$. 


\section{Conclusions}

The comparison of the ability to drain infiltrated water from the system in the three rear-ventilated façade types studied has provided us a mean of determining the water entry rates into the cavity and onto the surface of the water resistive barrier of the test specimens. The results obtained have reported the highest water infiltration rates into the cavity in the rear-ventilated façade system made of fibre cement cladding panels riveted to vertical top hat sections (mock-up 01). As opposed, the lower infiltration rate percentages into the cavity have been obtained for rear-ventilated façade system with fibre cement cladding panels hook on horizontal "C" sections (mock-up 02).

Concerning the water infiltration onto the surface of the water resistive barrier of the test specimens, the highest water entry rates have been obtained in the rearventilated façade system with fibre cement cladding panels hook on horizontal "C" sections (mock-up 02). To the contrary, the lowest water infiltration rate percentages onto the surface of the water resistive barrier have been reported for the rear-ventilated façade system made of fibre cement cladding panels riveted to vertical top hat sections (mock-up 01).

If all water infiltration rates into the wall system are considered, it can be concluded that the rear-ventilated façade system with riveted panels presents higher water ingress rates than the hook-on rear ventilated façade system.

As mentioned in the introduction, all these values are relevant as input for the boundary conditions in the hygrothermal simulations utilised to examine the moisture performance and durability of envelopes and wall assemblies. Note that according to ASHRAE 160, in the absence of specific full-scale test methods and data for the as-built exterior wall system, the default value for water penetration through the exterior surface shall be $1 \%$ of the water reaching that exterior surface. The present study and the existing ones clearly suggest that the value for moisture loads in the ASHRAE standard are somewhat conservative in respect to rearventilated facades.

\section{References}

1. ETAG 034 (2012).

2. CWCT, Standard for Systemized Building Envelopes (2006).

3. O. Birkeland, Norwegian Building Research Institute 36, 1963-1927 (1963).

4. M.R. Bassett, R.C. Bishop, NG Brown, Drained joints: Case studies, (1996).

5. W.C. Brown, G.A. Chown, G.F. Poirier, M.Z. Rousseau, CTU 34, 1-8 (1999).

6. G.A. Chown, W.C. Brown, G.F. Poirier, CTU 9, 1-6 (1997).

7. D.W. Finn, NRCC-38747 (1991).

8. CMHC, Rain penetration control: applying current knowledge (1999).
9. M.T. Kubal, Construction and Waterproofing Handbook (2008).

10. E.C.C. Choi, International Conference on Building Envelope Systems and Technology, 465-472 (1997).

11. G.K. Garden, CBD 55 (1964).

12. E.C.C. Choi, Water Leakage through Building Façades, 3-16 (1998).

13. J.F. Straube, $8^{\text {th }}$ Building Science and Technology Conference, 282-302 (2001).

14. K.K. Suresh, Building and Environment 35, 161179 (2000).

15. B. Blocken, J. Carmeliet, Journal of Wind Engineering and Industrial Aerodynamics 92, 10791130 (2004).

16. M.J. Lough, Exterior Enclosure Series (January 2011).

17. T. De Vogelaere, M. Pacco, Development of a numerical model for rainwater run-off on vertical planes extended with experimental verification, (University of Ghent, 2012).

18. B. Blocken, J. Carmeliet, Building and Environment 53, 59-73 (2012).

19. M.Y.L. Chew, P.P. Tan, Construction Building Materials 17, 181-187 (2003).

20. T. Van den Brande, B. Blocken, S. Roels, Building and Environment 64, 177-186 (2013).

21. R. Couper, $2^{\text {nd }}$ International CIB/RILEM Symposium on moisture problems in buildings (1974).

22. M. Rein, Fluid Dynamics Research 12, 61-93 (1993).

23. N.C. Reis, R.F. Griffiths, J.M. Santos, Journal of Computational Physics 198(2), 747-770 (2004).

24. M. Abuku, H. Janssen, J. Poesen, S. Roles, Building and Environment 44(1), 113-24 (2009).

25. J. Liu, H. Vu, S.S. Yoon, R.A. Jepsen, G. Aguilar, Atomization and Sprays 20(4), 297-310 (2010).

26. A. Erkal, D. D'Ayala, L. Sequeira, Building and Environment 57, 336-348 (2012).

27. O. Birkeland, RILEM/CIB Symposium on Moisture Problems in Buildings, 16-19 (1965).

28. B.H. Vos, E. Tammes, CIB W40 Meeting (1976).

29. O. Beijer, A. Johansson, CIB Research Report No. 7:76, (1976).

30. O. Beijer, RILEM/ASTM/CIB Symposium on Evaluation of the Performance of External Vertical Surfaces of Buildings, 67-76 (1977).

31. C. Carll, $2^{\text {nd }}$ Annual Conference on Durability and Disaster Mitigation in Woodframe Housing, 33-40 (2001).

32. T.G. Bitsuamlak, A.G. Chowdhury, D. Sambare, Building and Environment 44, 2430-2441 (2009).

33. N. Sahal, M.A. Lacasse, Building and Environment 43, 1250-1260 (2008). 
34. M.A. Lacasse, M.Z. Rousseau, S.M Cornick, S. Plescia, NRCC-47685, $10^{\text {th }}$ Canadian Conference on Building Science and Technology, 127-138 (2005).

35. M.A. Lacasse, T. O'Connor, S. C. Nunes, P. Beaulieu, IRC-RR-133, NRC-CNRC (2003).

36. M.A. Lacasse, M. Z. Rousseau, S.M. Cornick, M.M. Manning, M. Nicholls, S.C. Nunes, Client Report B1229.1 (2008).

37. M.A. Lacasse, M. Manning, M. Rousseau, S.M. Cornick, S. Plescia, M. Nicholls, S. Nunes, NRCC49201, $11^{\text {th }}$ Canadian Conference on Building Science and Technology, 1-14 (2007).

38. M.A. Lacasse, H. Miyauchi, J. Hiemstra, Journal of ASTM International 6(6), 1-29 (2009).

39. A. Teasdale-St-Hilaire, D. Derome, ASHRAE Transactions 112(2), 656-670 (2006).

40. A. Teasdale-St-Hilaire, D. Derome, P. Fazio, $2^{\text {nd }}$ International Conference on Building Physics, 455462 (2003).

41. A. Teasdale-St-Hilaire, D. Derome, P. Fazio, Performance of the Exterior Envelopes of Whole Buildings IX (2004).

42. M.T. Bomberg, C.J. Shirtliffe, ASTM Manual Series, MNL-18, 453-461 (1994).

43. W. Nusselt, Zeitschrift VDI 60(28), 569-575 (1916).

44. M. El-Shimi, R. White, P. Fazio, Canadian Journal of Civil Engineering, 7(4):597-613 (1980).

45. C. Hall, A.N. Kalimeris, Building and Environment 19, 13-20 (1982).

46. C. Hall, A.N. Kalimeris, Canadian Journal of Civil Engineering 11, 108-111 (1984).

47. C. Hall, W.D. Hoff, Water transport in brick, sand and concrete (2002).

48. C. Hall, W.D. Hoff, Building and Environment 19(1), 13-20 (1984).

49. N. May, C. Sanders, Moisture in buildings: an integrated approach to risk assessment and guidance (2017).

50. BS EN ISO 13788 (2012).

51. BS EN 15026 (2007).

52. ASHRAE Standard 160 (2016).

53. J. Avellaneda, Medio ambiente: comportamiento y durabilidad del cerramiento (1982).

54. P. Huedo-Dordá, A.M. Pitarch-Roig, A. CentellesEcrig, L. Monfort-Gurrea, XI Foro global del recubrimiento cerámico, Qualicer'10 (2010).

55. F. Seo, S. Yoda, BRI Research Paper No.52 (1975).

56. T. Isaksen, RILEM/CIB Symposium on Moisture Problems in Buildings (1965).

57. M.A. Mas, J. Gutiérrez, E. Gil, A. Gil, V. Galvañ, Construction and Building Materials 25(4), 17531761 (2011).
58. J. Fernández-Madrid, J. López-Rivadulla, P. Alonso-Alonso, VI Congreso Internacional sobre Patología y Recuperación de Estructuras (2010).

59. C. Pardal, I. Paricio, La fachada ventilada y ligera, (2006).

60. T. Isaksen, Driving rain and joints: testing of model joints between elements (1972).

61. H. Ishikawa, $2^{\text {nd }}$ International CIB/RILEM Symposium on Moisture Problems in Buildings, Paper 2.3.1 (1974).

62. S. Sandor, B. Marton, Report No. 19 A/C (1968).

63. T. Isaksen, Report No. 93 (1964).

64. T. Isaksen, International CIB Symposium: Weathertight Joints for Walls, 265-269 (1967).

65. M.R.M. Hérbert, BRE CP 81/74 (1974).

66. M.R.M. Herbert, BRE CP 89/74 (1974).

67. M.R.M. Hérbert, H.W. Harrison, BRE CP 90 (1974).

68. M. Bassett, G. Overton, Buildings 2015 5, 130-148 (2015).

69. M. Abuku, B. Blocken, S. Roles, Journal of Wind Engineering and Industrial Aerodynamics 97(5-6), 197-207 (2009).

70. M. Arce-Recatalá, S. Garcia-Morales, N. Van den Bossche, Journal of Building Physics 42(1), 38-67 (2018).

71. FVHF (2015), Retrieved from: http://www.fvhf.de/facade/VHFSystem/Merkmale.p hp. 